\title{
COMPATIBILIZAÇÃO ENTRE O PLANEJAMENTO E O CONTROLE NO PROCESSO DE EXECUÇÃO DE OBRAS DE EDIFICAÇÕES VERTICAIS: UM ESTUDO MULTICASO NA CIDADE DE JOÃO PESSOA-PB
}

\author{
N. M. C. ARAÚJo*; L. L. AVELINO, V. S. ARAúJo \\ Instituto Federal de Educação, Ciência e Tecnologia da Paraíba \\ nelmamca@gmail.com ${ }^{*}$
}

Submetido 06/02/2018 - Aceito 20/12/2018

DOI: $10.15628 /$ holos.2018.6901

\section{RESUMO}

Os desafios, peculiaridades e especificidades dos empreendimentos da construção civil tornam os modelos de gestão atuais insuficientes para garantir, de forma satisfatória, o alcance dos objetivos propostos. Características como a dificuldade de elaboração de um planejamento específico e um controle de custos, a existência de um grande número de interdependências entre os projetos que compõem o empreendimento, a necessidade de velocidade significativa de respostas para a tomada de decisões e o grande número de intervenientes, contribuem de forma significativa para que o cenário da construção civil seja desafiador para qualquer metodologia de gestão. Este artigo apresenta parte dos resultados de uma pesquisa, realizada em empresas construtoras de edificações verticais da cidade de João Pessoa-PB, que tinha como objetivos investigar se as empresas construtoras realizam o planejamento e o controle de custos dos seus empreendimentos, se há compatibilidade entre eles e se utilizam a compatibilização como subsídio na tomada de decisões. Ao todo foram pesquisadas 10 empresas construtoras, todas cadastradas junto ao Sinduscon-JP. Os resultados apontam que todas as empresas realizam 0 planejamento e o controle de custos dos seus empreendimentos, no entanto, não há compatibilidade entre eles e, consequentemente, não podem ser utilizados na tomada de decisões pelos seus gestores.

PALAVRAS-CHAVE: Construção civil, planejamento, controle, compatibilização.

\section{COMPATIBILITY BETWEEN PLANNING AND CONTROL IN THE PROCESS OF IMPLEMENTATION OF VERTICAL BUILDINGS: A MULTICOLE STUDY IN THE CITY OF JOÃO PESSOA-PB}

\begin{abstract}
The challenges, peculiarities and specificities of civil construction projects make current management models insufficient to guarantee, in a satisfactory way, the achievement of the proposed objectives. Characteristics such as the difficulty of elaborating a specific planning and cost control, the existence of a large number of interdependencies between the projects that make up the enterprise, the need for a significant speed of responses to the decision making and the large number of stakeholders, contribute significantly to the construction scenario being challenging for any management methodology. This
\end{abstract}

article presents part of the results of a survey carried out in vertical building companies of the city of João Pessoa-PB, whose objective was to investigate whether construction companies carry out the planning and cost control of their projects, whether there is compatibility between and they use compatibilization as a subsidy in decision-making. In all, 10 construction companies were surveyed, all registered with Sinduscon-JP. The results indicate that all companies carry out the planning and cost control of their projects, however, there is no compatibility between them and, consequently, they can not be used in decision making by their managers.

KEYWORDS: Building construction, planning, control, compatibilization. 


\section{INTRODUÇÃO}

O cenário econômico mundial dos últimos anos tem conduzido o Brasil a um caminho de grandes desafios nos diversos segmentos industriais, dentre os quais o da construção civil (Meira e Araújo, 2016).

A fórmula para o sucesso não é simples nesse contexto de mudanças e requerer das empresas construtoras ações rápidas e assertivas, para que sobrevivam em um mercado que se torna, a cada dia, fortemente competitivo.

O aumento da competitividade no setor e o aumento da complexidade dos projetos na construção civil têm exigido das empresas construtoras a adoção de melhores práticas de gestão (Polito, 2015).

Os desafios, peculiaridades e especificidades dos empreendimentos da construção civil tornam os modelos de gestão atuais insuficientes para garantir, de forma satisfatória, o alcance dos objetivos propostos. Características como a dificuldade de elaboração de um planejamento específico e um controle de custos, a existência de um grande número de interdependências entre os projetos que compõem o empreendimento, a necessidade de velocidade significativa de respostas (tomada de decisões) e o grande número de intervenientes, fazem com que o cenário da construção civil seja desafiador para qualquer metodologia de gestão.

O desafio a ser vencido é garantir o alcance das metas pré-estabelecidas, convivendo com as incertezas. Mesmo nas empresas que adotam boas práticas metodológicas de gerenciamento de prazo, custos e qualidade, não existe garantia de sucesso do empreendimento.

Ressalta-se, ainda, que muitos empreendimentos fracassam por negligenciar áreas consideradas "menos importantes", pelos gestores, como, por exemplo, recursos humanos, segurança e saúde no trabalho, suprimentos, gerenciamento de riscos, entre outras.

Consoante Polito $(2015$, p. 23$)$, "podemos afirmar, sem medo de errar, que a maioria dos problemas encontrados em nossos canteiros de obra, e que impactam nosso resultado, não são de ordem técnica e sim gerencial".

Nesse contexto, este artigo apresenta parte dos resultados de uma pesquisa que teve como objetivos investigar se as empresas construtoras de edificações verticais de João Pessoa realizam o planejamento e o controle de custos dos seus empreendimentos, se há compatibilidade entre eles e se utilizam a compatibilização como subsídio na tomada de decisões.

De um modo geral, o planejamento das empresas construtoras presentes no mercado da grande João Pessoa tem se resumido à elaboração do orçamento e dos cronogramas físico e físico-financeiro, enquanto que o controle de custos está fundamentado na identificação de variações negativas entre os custos orçados e os custos reais, podendo interferir na qualidade dos empreendimentos e na competitividade dessas empresas no mercado cada vez mais exigente e competitivo.

De acordo com Ávila (2001), as empresas construtoras preocupam-se em apurar custos de maneira a atender às exigências legais, com vistas à avaliação dos estoques e à composição dos balanços. Também visam a tomada de decisão e o exercício de processos de controle, bem como amparar o construtor para a definição do preço dos produtos e serviços. 
Como a maioria das empresas apresenta áreas de gerenciamento pouco dominadas ou com deficiência no fluxo de informações, opções de compatibilização do planejamento e do controle de custos podem oferecer, às empresas construtoras, condições reais/adequadas para comparar o que foi orçado com o realizado, definir preços e, principalmente, decidir sobre estratégias para enfrentar a concorrência com base em dados próprios e reais, dando-lhes rapidez e segurança de respostas.

Assim, o diagnóstico quanto às ações de planejamento e controle de custos utilizadas pelas empresas construtoras e a definição de formas de compatibilização entre estas proporcionarão, às empresas, segurança nas tomadas de decisão pelos gestores, com vistas à qualidade de execução dos seus respectivos empreendimentos e à competitividade mercadológica.

\section{PLANEJAMENTO DE OBRAS}

Segundo Mattos (2010, p. 17), “o planejamento da obra é um dos principais aspectos do gerenciamento, conjunto de amplo espectro, que envolve também orçamento, compras, gestão de pessoas, comunicações etc.".

Mattos (2010) afirma que, ao planejar uma obra, o gestor adquire alto grau de conhecimento do empreendimento (obra), o que lhe permite ser mais eficiente na condução dos trabalhos e afirma que os principais benefícios que o planejamento traz são:

- Conhecimento pleno da obra;

- Deteç̧ão de situações desfavoráveis;

- Agilidade de decisões;

- Relação com o orçamento;

- Otimização da alocação dos recursos;

- Referência para acompanhamento;

- Padronização;

- Referência para metas;

- Documentação e rastreabilidade;

- Criação de dados históricos;

- Profissionalismo.

A realidade da maioria das empresas construtoras, em todo o país, é não possuir planejamento de suas obras ou, quando possuem, apresentarem inadequações relevantes. Essa constatação é mais acentuada em obras de pequeno e médio portes, sejam elas incorporações ou não.

Pode-se encontrar no mercado, seja ele nacional, regional ou local, empresas que planejam, mas o fazem de forma equivocada, com resultados muito aquém; empresas que planejam bem, mas não executam o controle deste; e empresas que não planejam e não controlam, realizando suas atividades de forma totalmente improvisada, se valendo, na maioria das vezes, da experiência do engenheiro de obras e/ou do mestre de obras.

A deficiência do planejamento pode resultar em consequências desastrosas, tanto para a própria obra quanto para a empresa construtora responsável pela execução da obra. As principais consequências de um planejamento mal elaborado ou da ausência de planejamento 
são: descumprimento de prazo; estouro do orçamento; indisposição com clientes; litígios judiciais.

\section{CONTROLE DE OBRAS}

O controle permite a obtenção das informações necessárias à correção de rumo do planejamento, quando necessária, constituindo-se em um ciclo de retroalimentação, como mostra a Figura 1.

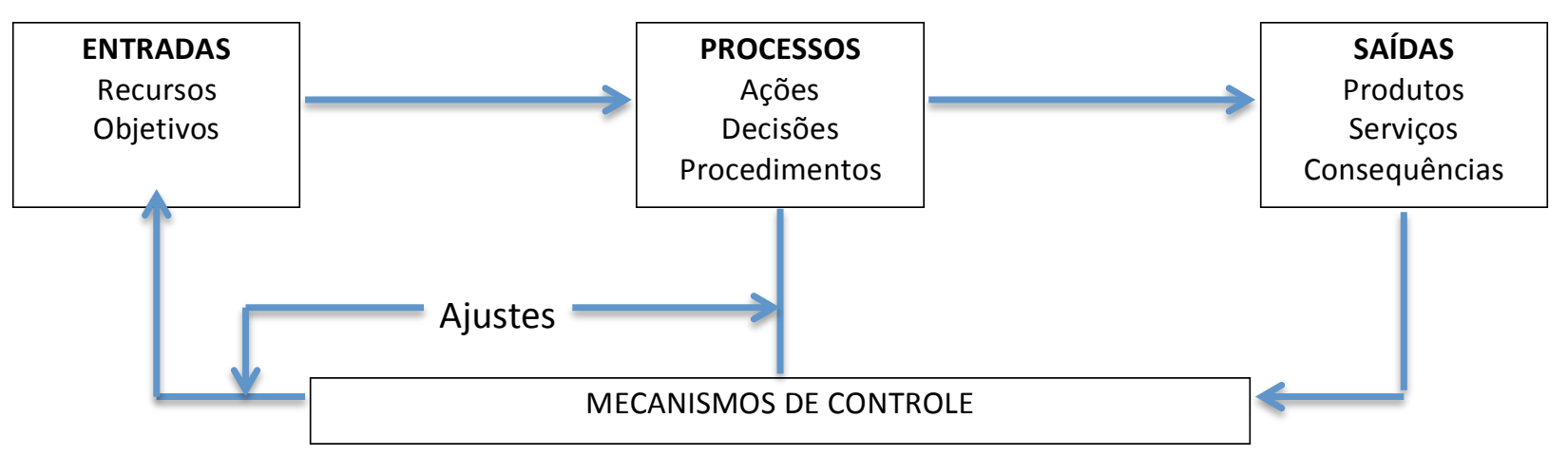

Figura 1: Ciclo de retroalimentação do projeto. Fonte: Adaptado de Limmer (1997).

Não se observa com muita frequência a preocupação das empresas construtoras com a gestão e controle de custos, além do levantamento desses para o cálculo de preços e execução de orçamentos. Silva e Lins (2013) afirmam que controle de custos por obras, por atividades, gestão de processos e avaliação de desempenho por segmentos são controles gerenciais raros de serem observados entre as atividades rotineiras de gestão, apesar de haver consciência por parte dos gestores da necessidade de melhor controle e gestão dos custos. O controle de custo é de longe o que possui maior importância para os gestores.

Tisaka (2006) afirma que no cálculo do custo de execução de uma obra devem ser considerados:

- Despesas diretas e indiretas de mão de obra;

- Despesas de materiais e insumos;

- Outras despesas;

- Lucro e direitos autorais.

A literatura clássica de gestão de custos não aborda com frequência a aplicação de metodologias de custeio e controle de gastos de forma específica para a indústria da construção. No entanto, os conceitos, nomenclatura e aplicações de custos são de aplicação geral para todos os segmentos, sejam de produção manufaturada ou de serviços, ainda que adaptações sejam por vezes necessárias, face às seguintes características (SILVA e LINS, 2013):

- Cada obra possui características próprias e raramente é reproduzida;

- O processo de fabricação é por ordem de produção e não por produção em série; 
- Diversas obras em processo de construção simultâneo em condições e locais distintos;

- Trata-se de um processo de produção de longo prazo e por isso necessita de tratamento contábil específico;

- Processos diversificados com níveis diferenciados de atividades e consumo de recursos.

Existem metodologias consagradas para a realização do controle de custos, tais como custeamento por departamentos ou centros de custos, custeio por atividades e gestão de processos. Essas metodologias podem e devem ser adotadas pelas empresas construtoras nas suas atividades de controles gerenciais.

\section{METODOLOGIA}

\subsection{Tipo de Pesquisa}

Considerando-se o critério de classificação de pesquisa proposto por Vergara (2009), quanto aos fins e quanto aos meios, a pesquisa realizada classifica-se em exploratória e descritiva, quanto aos fins, e de campo, bibliográfica e participante, quanto aos meios de investigação.

\subsection{Universo e Amostra}

O universo da pesquisa foi composto pelas empresas construtoras de edificações verticais cadastradas junto ao Sindicato da Indústria da Construção Civil de João Pessoa (Sinduscon-JP).

Já a amostra, foi composta pelas dez maiores empresas construtoras, no que diz respeito ao volume de obras construído, com atuação na grande João Pessoa, e que aceitaram participar da pesquisa. Ressalta-se, ainda, que todas as empresas possuíam, no momento da pesquisa, empreendimentos em construção que dispunham de orçamentos (de custo e/ou de venda) e cronogramas (físicos e/ou físico-financeiros).

\subsection{Coleta de Dados}

De acordo com Barros e Lehfeld (2007), a coleta de dados é a fase da pesquisa em que se indaga a realidade e se obtêm dados pela aplicação de técnicas. A coleta de dados da pesquisa se deu em dois momentos: no primeiro momento, com relação à pesquisa bibliográfica; no segundo, com relação à pesquisa documental e de campo.

Na pesquisa bibliográfica, os dados foram coletados através de fichas resumos oriundas de teses, dissertações, monografias, artigos e livros que tinham relação com o tema da pesquisa.

Já na pesquisa documental, houve a análise do conteúdo dos orçamentos e cronogramas elaborados pelas empresas pesquisadas, enquanto que na pesquisa de campo, os dados foram coletados por meio de roteiros de observação, os quais foram elaborados a partir da pesquisa bibliográfica.

Antes da aplicação definitiva dos roteiros de observação, estes foram previamente testados, com o intuito de corrigir distorções que porventura se apresentassem. Ressalta-se que não houve necessidade de corrigir as ferramentas utilizadas. 
Os roteiros de observação foram utilizados pelas pesquisadoras quando da visita in loco aos setores responsáveis pela elaboração dos orçamentos e dos cronogramas e aos canteiros de obra pesquisados. Essas ferramentas buscaram identificar a existência, ou não, de compatibilização entre o planejamento e o controle de custos, bem como de conhecimento, por parte dos gestores, das formas de compatibilização entre o planejamento e o controle de custos e a utilização desta como subsídio real na tomada de decisão.

\subsection{Tratamento dos Dados}

Os dados foram tratados de forma quantitativa, utilizando-se procedimentos estatísticos, e qualitativa, através da estruturação e análise destes.

\section{RESULTADOS E DISCUSSÕES}

\subsection{Empresas construtoras}

As principais características das 10 empresas construtoras pesquisadas são apresentadas no Quadro 1.

Quadro 1: E Principais características das empresas pesquisadas.

\begin{tabular}{|c|c|c|c|c|c|c|}
\hline \multirow[t]{2}{*}{ Empresas } & \multirow{2}{*}{$\begin{array}{l}\text { Tempo de } \\
\text { atuação } \\
\text { (anos) }\end{array}$} & \multirow{2}{*}{$\begin{array}{l}\text { Atuação } \\
\text { geográfica }\end{array}$} & \multirow{2}{*}{$\begin{array}{l}\text { Número de } \\
\text { funcionários }\end{array}$} & \multirow{2}{*}{$\begin{array}{c}\text { Número de } \\
\text { obras em } \\
\text { andamento }\end{array}$} & \multicolumn{2}{|c|}{$\begin{array}{c}\text { Utilização de consultoria para } \\
\text { planejamento }\end{array}$} \\
\hline & & & & & Sim & Não \\
\hline$A$ & 10 & Regional & 600 & 6 & $x$ & \\
\hline$B$ & 9 & Local & 120 & 4 & $x$ & \\
\hline$C$ & 20 & Local & 150 & 3 & & $x$ \\
\hline $\mathrm{D}$ & 47 & Local & 250 & 4 & & $x$ \\
\hline$E$ & 28 & Regional & 450 & 5 & & $x$ \\
\hline $\mathrm{F}$ & 30 & Regional & 400 & 4 & & $x$ \\
\hline $\mathrm{G}$ & 30 & Local & 200 & 4 & $x$ & \\
\hline $\mathrm{H}$ & 20 & Local & 150 & 3 & & $x$ \\
\hline 1 & 28 & Local & 180 & 4 & & $x$ \\
\hline $\mathrm{J}$ & 17 & Local & 160 & 3 & & $x$ \\
\hline
\end{tabular}

As empresas pesquisadas possuem atuação no mercado que vai de 9 até 47 anos, sendo que, das 10 empresas pesquisadas: apenas duas empresas (empresas A e B) atuam no mercado há no mínimo 10 anos; três empresas (empresas $\mathrm{C}, \mathrm{H}$ e J) atuam há 11-20 anos; quatro empresas (empresas $E, E, G$ e I) atuam há 21-30 anos; e apenas uma empresa (empresa D) atua há mais de 40 anos.

A atuação da maioria das empresas (60\%) é local, entendendo-se como local a região metropolitana de João Pessoa, que compreende 12 municípios (Alhandra, Bayeux, Caaporã, Cabedelo, Conde, Cruz do Espírito Santo, João Pessoa, Lucena, Pitimbu, Pedras de Fogo, Rio Tinto e Santa Rita). Todavia, ressalta-se que as empresas pesquisadas, com atuação local, se limitam a construir seus empreendimentos apenas nos municípios de João Pessoa e Cabedelo.

O número total de funcionários das empresas possui variação significativa (120 a 600 funcionários), entretanto, deve-se ressaltar que essa variação está diretamente relacionada com as etapas construtivas em que se encontram os seus respectivos empreendimentos (obras). Tomando como base o número de empreendimentos em execução no momento da pesquisa 
(2017), a média de funcionários por empreendimento é igual a, aproximadamente, 71 funcionários. Utilizando-se como referencial a classificação adotada pelo SEBRAE (Serviço Brasileiro de Apoio às Micro e Pequenas Empresas) quanto ao porte das empresas, levando-se em conta o número de funcionários, apenas uma empresa é classificada como de grande porte (500 ou mais funcionários), que é a empresa $A$, enquanto que as demais empresas são classificadas como de médio porte (de 100 a 499 funcionários).

Apenas três empresas (30\%) utilizam consultoria de planejamento na execução dos seus empreendimentos (empresas A, B e G). As demais empresas não dispõem de consultoria para o planejamento dos seus empreendimentos porque possuem profissional específico, dentro dos seus respectivos quadros funcionais, para realizar o planejamento de todos os seus empreendimentos. Esse profissional é, na maioria das empresas pesquisadas que não utilizam o planejamento ( 5 empresas de um total de $7=71,4 \%$ ), um engenheiro civil, enquanto que nas outras duas empresas é um tecnólogo em construção de edifícios.

Todas as empresas pesquisadas afirmam ser o planejamento uma ferramenta de grande importância para o sucesso do empreendimento, desde o estudo de viabilidade até a conclusão total (entrega) da obra.

\subsection{Planejamento}

As ferramentas de planejamento mais utilizadas pelas empresas pesquisadas são o orçamento e os cronogramas (físico e físico-financeiro). Todas as empresas utilizam essas ferramentas e algumas delas (40\%) também utilizam check lists e linhas de balanço nos seus planejamentos.

Nenhuma das empresas pesquisadas utiliza algum software específico de planejamento/gerenciamento de obras para elaborar o seu planejamento, utilizando somente o Excel da Microsoft, que compõe o Office. Através do Excel são elaboradas as planilhas orçamentárias e os cronogramas.

Todas as empresas pesquisadas afirmam realizar reuniões semanais de planejamento e que participam dessas reuniões o engenheiro residente, o mestre de obras e o técnico de edificações. Em três das empresas pesquisadas (30\%), além dos profissionais anteriormente citados, também participam o responsável pelo planejamento da obra (engenheiro civil ou tecnólogo em construções). Em outras duas empresas (20\%), os estagiários (de engenharia civil ou de tecnologia em construção de edifícios) também participam das reuniões de planejamento.

As questões que são discutidas sempre nas reuniões, por todas as empresas pesquisadas, dizem respeito ao cumprimento do cronograma físico e às reformas solicitadas pelos clientes. Além dessas questões, também são discutidos, por algumas das empresas pesquisadas, temas como compatibilização de projetos, Procedimentos de Execução de Serviços (PES) e segurança do trabalho.

Nenhuma das empresas pesquisadas tem o hábito de elaborar atas de reuniões, ficando as decisões tomadas, quanto a assuntos, responsabilidades e prazos, apenas na memória dos seus participantes, ou seja, não há qualquer tipo de registro documental da realização das reuniões.

\subsection{Controle}


Todas as empresas pesquisadas afirmam que realizam o controle de suas respectivas obras e que esse controle diz respeito aos serviços, aos materiais e aos resíduos gerados. Também afirmam que esse controle é diário e que são comparados com as ferramentas utilizadas no planejamento da obra (orçamento e cronogramas), no que diz respeito aos serviços.

Os responsáveis pela realização das atividades de controle diferem entre as empresas pesquisadas: duas empresas (20\%) têm como responsáveis o engenheiro residente, os técnicos em edificações e em segurança do trabalho, o tecnólogo em construção de edifícios, o mestre, o encarregado e os estagiários (engenharia civil e tecnologia em construção de edifícios); em cinco empresas $(50 \%)$ a responsabilidade do controle é do engenheiro residente, dos técnicos em edificações e em segurança do trabalho, do mestre e do encarregado; e em três (30\%) empresas são responsáveis pelo controle o engenheiro residente, o mestre de obras e os estagiários (engenharia civil e tecnólogo em construção de edifícios).

Na maioria das empresas pesquisadas (70\%) a mensuração dos serviços executados é realizada por unidades físicas, enquanto que em $30 \%$ das empresas é realizada tanto por unidades físicas quanto por percentual.

O controle de materiais, estoque e distribuição, é realizado por todas as empresas pesquisadas, sendo a responsabilidade deste do almoxarife e dos estagiários. Esse controle se resume a anotações das quantidades distribuídas, com seus respectivos locais de aplicação, e estocadas.

Já o controle dos resíduos gerados é realizado, em todas as empresas pesquisadas, pelos técnicos em edificações. Esse controle se resume a anotações do volume de resíduos transportado, em caçambas estacionárias, pelas empresas de transporte de resíduos. Esse controle serve basicamente para aferição dos valores pagos às empresas transportadoras. Ressalta-se que os técnicos também são responsáveis pelo arquivamento das vias do formulário de Controle de Transporte de Resíduos (CTR), que são exigidos pela Autarquia Especial Municipal de Limpeza Urbana (EMLUR).

\section{CONCLUSÃO}

As empresas construtoras pessoenses têm trabalhado de forma muito incipiente as ferramentas de planejamento e controle de obras. O planejamento tem se restringido apenas à elaboração do orçamento, cronogramas físico e físico-financeiros e linha de balanço, enquanto que o controle tem sido apenas dos serviços executados (unidades físicas ou percentuais) e da distribuição dos materiais, em termos quantitativos.

Não há uma compatibilização entre as ferramentas de planejamento e de controle, dificultando a tomada de decisões por parte dos gestores. O controle de custos não é utilizado em sua forma plena, o que permitiria maior segurança na tomada de decisões.

As principais aplicações das informações de custos têm sido tão somente para fins contábeis, especialmente no que diz respeito à avaliação dos valores de estoques e apuração do resultado, e para fins de tomada de decisão.

Por fim, conclui-se ser perfeitamente possível e necessário que as ferramentas de gestão e controle de custos (Análise SWOT; Matriz GUT; EAP - Estrutura Analítica de Projeto; AVA - 
Análise do Valor Agregado; PERT-CPM; Cronograma de Prazos e Tarefas, por exemplo) possam auxiliar as atividades gerenciais visando maior eficiência e melhoria do resultado operacional. Com a aplicação dessas ferramentas, a curto e médio prazos, as empresas podem obter: melhores condições para conduzir de forma eficiente os serviços das diversas etapas construtivas; possibilidade de detectar, em um menor espaço de tempo, possíveis situações desfavoráveis e tomar, de forma rápida, decisões compatíveis com as demandas existentes; otimização na alocação de recursos, físicos e financeiros; padronização, unificando entendimentos na equipe quanto ao plano de ataque da obra; base de dados confiável para aprimoramento das ações de planejamento, principalmente de orçamentos e cronogramas.

\section{REFERÊNCIAS}

Ávila, A. V. (2001). Custos industriais. Palhoça: UNISUL (Apostila, Departamento de Engenharia de Produção).

Barros, A. J. S.; Lehfeld, N. A. S. (2007). Fundamentos de metodológica científica. 3. ed. São Paulo: Pearson Prentice Hall.

Limmer, C. V. (1997). Planejamento, orçamentação e controle de projetos e obras. Rio de Janeiro: LTC.

Mattos, A. D. (2010). Planejamento e controle de obras. São Paulo: Pini.

Meira. A. R.; Araújo, N. M. C. (2016). Qualidade na construção civil. João Pessoa: IFPB.

Polito, G. (2015). Gerenciamento de obras: boas práticas para a melhoria da qualidade e da produtividade. São Paulo: Pini.

Silva, R. N. S.; Lins, L. S. (2013). Gestão de custos: contabilidade, controle e análise. 2. ed. São Paulo: Atlas.

Tisaka, M. (2006). Orçamento na construção civil: consultoria, projeto e execução. São Paulo: Pini. Vergara, S. C. (2009). Projetos e relatórios de pesquisa em administração. 11. ed. São Paulo: Atlas. 